\title{
HUBUNGAN KEPEMIMPINAN KEPALA RUANGAN DENGAN PELAKSANAAN TIMBANG TERIMA OLEH PERAWAT DI RUANG RAWAT INAP RUMAH SAKIT UMUM DAERAH TAMIANG LAYANG
}

\author{
Lucia Andi Chrismilasari ${ }^{1}$, Septi Machelia C.N ${ }^{2}$, Ferra Handieni ${ }^{3}$ \\ ${ }^{1,2,3}$ Sekolah Tinggi Ilmu Kesehatan Suaka Insan \\ Email: septi01nursery@gmail.com
}

\begin{abstract}
The implementation of handover in the hospital is not optimal because it is often not implemented in accordance with the standard operating procedures established by the hospital, especially related with the presence of the chief nurse. The absence of a chief nurse as a leader will hinder the smooth implementation of handover. This study aimed to identify the relationship between leadership of the chief nurse with the implementation of handover by nurses in the inpatient room at Tamiang Layang Hospital. This research was an analytic study with a cross sectional approach. Population for this study was all nurses in the inpatient Room at Tamiang Layang Hospital, 75 people. Sample for this research was 43 nursing gathered by using simple random sampling technique. Data analysis through Spearman Rank test with $95 \%$ confidence level. The results of this study indicated that leadership of the chief nurse was mostly in good category as many as 30 people (69.8\%) and the handover was carried out well as many as 32 people (74.4\%). There was a relationship between leadership of the chief nurse with the implementation of handover at the Tamiag Layang Hospital $(p=0.000<$ $0.05, r=0.891)$. This study concludes that there was a relationship between the leadership of the chief nurse and the implementation of the handover at the Tamiyang Layang Hospital. The hospital should urge the chief nurse to be more active in participating in the implementation of handover.
\end{abstract}

Keywords: leadership, head of the room, weigh-in, hospitalization

\begin{abstract}
Abstrak
Pelaksanaan timbang terima belum optimal karena seringkali tidak selalu dilakukan sesuai dengan Standar Operasional Prosedur yang telah ditetapkan rumah sakit, terlebih apabila tanpa kehadiran kepala ruangan. Tidak adanya peran yang baik dari seorang kepala ruang sebagai seorang pimpinan akan menghambat kelancaran pelaksanaan timbang terima. Penelitian ini bertujuan untuk mengidentifikasi hubungan kepemimpinan kepala ruangan dengan pelaksanaan timbang terima oleh perawat di ruang rawat inap RSUD Tamiang Layang. Penelitian ini adalah penelitian analitik dengan pendekatan cross sectional. Populasi adalah seluruh perawat pelaksana di Ruang rawat Inap RSUD Tamiang Layang 75 orang. Sampel berjumlah 43 dengan teknik pengambilan simple random sampling. Analisis data melalui uji Spearman Rank dengan tingkat kepercayaan 95\%. Hasil penelitian ini menunjukkan bahwa kepemimpinan kepala ruangan sebagian besar sudah dengan kategori baik yaitu sebanyak 30 orang $(69,8 \%)$ dan timbang terima terlaksana dengan baik sebanyak 32 orang $(74,4 \%)$. Ada hubungan antara kepemimpinan kepala ruangan dengan pelaksaaan timbang terima di RSUD Tamiyang Layang $(\mathrm{p}=0,000<\alpha 0,05, \mathrm{r}=0,891)$. Penelitian ini menyimpulkan bahwa ada hubungan antara kepemimpinan kepala ruangan dengan pelaksaaan timbang terima di RSUD Tamiyang Layang. Pihak rumah sakit hendaknya menghimbau kepala ruangan agar dapat lebih aktif mengikuti pelaksanaan timbang terima pasien
\end{abstract}

Kata Kunci: kepemimpinan, kepala ruangan, timbang terima, rawat inap

\section{PENDAHULUAN}

Timbang terima atau yang dikenal dengan operan merupakan teknik atau cara untuk menyampaikan atau menerima sesuatu atau laporan yang berkaitan dengan keadaan klien. Operan klien harus dilakukan seefektif mungkin dengan menjelaskan secara singkat, jelas dan lengkap tentang tindakan mandiri perawat, 
Jurnal Keperawatan Suaka Insan (JKSI) Vol. 6, No. 1, Juni 2021

tindakan kolaboratif yang sudah dan belum dilakukan, serta perkembangan klien saat itu. Informasi yang disampaikan harus akurat sehingga kesinambungan asuhan keperawatan dapat berjalan dengan sempurna (Suni, 2018).

Timbang terima merupakan salah satu kegiatan yang dilakukan individu perawat dalam lingkungan pelayanan keperawatannya atau bisa digolongkan dalam sebuah perilaku kerja karena didalamnya terdapat aktivitas berdiskusi, mencatat, berkomunikasi dengan sejawat dan pasien. Faktorfaktor yang mempengaruhi perilaku dan kinerja seseorang adalah faktor individu, faktor psikologis dan faktor organisasi. Faktor individu meliputi kemampuan, latar belakang dan demografi, faktor psikologis meliputi persepsi, sikap, kepribadian dan motivasi sedangkan dari faktor organisasi meliputi sumber daya, imbalan, struktur, desain pekerjaan serta kepemimpinan (Tribowo, 2013).

Kepemimpinan yang paling dekat dalam pengawasan pelaksanaan timbang terima adalah kepala ruang. Kepala ruang mempunyai andil bahkan berperan langsung dalam pelaksaaan timbang terima. Peran kepala ruangan sebagai seorang pimpinan mempunyai banyak hal yang erat kaitannya dengan fungsi manajemen mulai dari perencanaan, pengorganisasian, pengarahan dan pengawasan. Adanya peran yang baik dari seorang kepala ruangan sebagai seorang pimpinan atau manajer dalam dan selama proses pelaksanaan timbang terima diharapkan akan dapat memperlancar timbang terima dalam layanan keperawatan (Istiningtyas, 2018).

Semakin luas proses timbang terima (lebih banyak peserta dalam kegiatan timbang terima), peran pemimpin menjadi sangat penting untuk mengelola timbang terima pasien di klinis. Pemimpin harus memiliki pemahaman yang komprehensif dari proses timbang terima pasien dan perannya sebagai pemimpin. Tindakan segera harus dilakukan oleh pemimpin pada eskalasi pasien yang memburuk (Tribowo, 2013).

Saat observasi di dua ruangan rawat inap RSUD Tamiang Layang pada tanggal 18 - 19 Maret 2019 menunjukkan perbandingan dan perbedaan pelaksanaan timbang terima yang diikuti kepala ruangan dan tidak diikuti kepala ruangan. Pelaksanaan timbang terima yang tidak diikuti kepala ruangan terlihat tidak sesuai dengan SOP misalnya terdapat perawat yang terlambat datang waktu pelaksanaan timbang terima, terdapat perawat sengaja tidak mengikuti timbang terima dengan alasan ada pekerjaan lain dan serta pelaksanaan timbang terima pasien tidak dilakukan berkeliling ke ruang masing-masing pasien sedangkan pada 1 ruangan yang diikuti kepala ruangan pelaksanaan timbang terima sesuai dengan SOP yang telah ditetapkan.

Hasil wawancara singkat yang dilakukan kepada salah satu kepala ruangan mengatakan bahwa pelaksanaan timbang terima memang belum optimal karena tidak selalu dilakukan sesuai dengan SOP yang telah ditetapkan rumah sakit, terlebih apabila tanpa kehadiran kepala ruangan di nurse station saat timbang terima berlangsung. Tetapi, saat ada kepala ruangan, perawat pelaksana merasa ada pengawasan dan akan melakukan langkah timbang terima sesuai SOP. Wawancara singkat juga dilakukan terhadap beberapa perawat yang mengatakan bahwa keberadaan kepala ruangan pada saat pelaksanaan timbang terima seringkali membuat perawat pelaksana tersebut merasa di awasi dan takut mendapatkan teguran jika tidak sesuai dengan SOP rumah sakit. Hal ini sangat disayangkan karena pihak manajerial mengharapkan dengan adanya sosialisasi SOP timbang terima dan penetapan timbang terima pada SK Direktur RSUD Tamiang Layang nomor 444.1/64.1/SKP/RSUD-TL/2017, diharapkan timbang terima berjalan secara optimal.

Data dari ruang rawat inap RSUD Tamiang Layang terdapat dampak yang diperoleh pasien dari pelaksanaan timbang terima yang tidak optimal diantaranya tercatat 2 pasien yang mendapatkan pengobatan yang tidak sesuai dengan ketentuan, terdapat 4 pasien yang mendapatkan pelayanan kesehatan seperti rontgen dan operasi tidak sesuai jadwal yang telah ditentukan sebelumnya. Hal ini menunjukkan bahwa adanya kesalahan dalam komunikasi timbang terima tersebut akan merugikan pasien.

Beberapa hal yang sudah dijelaska ini mendorong perlunya dilakuan penelitian lebih jauh tentang "Hubungan Kepemimpinan Kepala Ruangan dengan Pelaksanaan Timbang Terima oleh Perawat di Ruang Rawat Inap RSUD Tamiang Layang".

\section{METODE PENELITIAN}

Jenis penelitian ini adalah kuantitatif. Rancangan penelitian yang digunakan adalah analitik dengan pendekatanan cross sectional. Penelitian ini dilaksanakan di Ruang rawat Inap Boegenvile, Mawar, Tulip, Anggrek, Asoka, Melati, Edelwies dan ICU Rumah Sakit Umum 
Jurnal Keperawatan Suaka Insan (JKSI) Vol. 6, No. 1, Juni 2021

Daerah Tamiang Layang. Populasi dalam penelitian ini adalah seluruh perawat pelaksana di Ruang rawat Inap RSUD Tamiang Layang sebanyak 75 orang. Sampel berjumlah 43 orang dengan teknik pengambilan acak sederhana (simple random sampling). Variabel bebas adalah kepemimpinan kepala ruangan sedangkan variabel terikat adalah pelaksanaan timbang terima.

Instrumen berupa kuesioner dan lembar observasi. Kuesioner kepemimpinan kepala ruangan telah dilakukan uji validitas dan reliabilitas kepada 20 orang perawat pelaksana di RSUD Tamiang Layang pada tanggal $28-31$ Mei 2019. Hasil uji validitas didapatkan nilai $r$ hitung seluruh pertanyaan kepemimpinan kepala ruangan pada rentang $0,457-0,748$, dengan demikian disimpulkan bahwa seluruh pertanyaan kuesioner tersebut adalah valid. Nilai alpha cronbach kuesioner kepemimpinan kepala ruangan pada rentang 0,749 , nilai ini lebih besar dari 0,60 dengan demikian kuesioner tersebut adalah reliabel. Analisis data terdiri dari univariat dan bivariat menggunakan uji Spearman Rank.

\section{HASIL PENELITIAN}

1. Karakteristik Responden

a. Tingkat pendidikan dan masa kerja Karakteristik responden berdasarkan umur dapat dilihat pada tabel 1.

Tabel 1 Tingkat pendidikan dan masa kerja Responden di Ruang Rawat Inap RSUD Tamiyang Layang.

\begin{tabular}{|c|c|c|c|}
\hline \multirow[b]{2}{*}{ No } & \multirow{2}{*}{$\begin{array}{c}\text { Tingkat } \\
\text { Pendidikan }\end{array}$} & \multicolumn{2}{|c|}{ Jumlah } \\
\hline & & $\begin{array}{c}\text { Frekuensi } \\
\text { (orang) }\end{array}$ & $\%$ \\
\hline 1 & Ners & 13 & 30,2 \\
\hline 2 & $\begin{array}{l}\text { S1 } \\
\text { Keperawatan }\end{array}$ & 0 & 0 \\
\hline \multirow[t]{2}{*}{3} & $\begin{array}{l}\text { D3 } \\
\text { Keperawatan }\end{array}$ & 30 & 69,8 \\
\hline & Jumlah & 43 & 100 \\
\hline \multirow[b]{2}{*}{ No } & \multirow[b]{2}{*}{$\begin{array}{l}\text { Masa } \\
\text { Kerja }\end{array}$} & \multicolumn{2}{|c|}{ Jumlah } \\
\hline & & $\begin{array}{c}\text { Frekuensi } \\
\text { (orang) }\end{array}$ & $\%$ \\
\hline 1 & $\begin{array}{l}\text { Baru }(\leq \\
3 \text { tahun })\end{array}$ & 6 & 14 \\
\hline 2 & $\begin{array}{l}\text { Lama } \\
(>3 \\
\text { tahun })\end{array}$ & 37 & 86 \\
\hline & Jumlah & 43 & 100 \\
\hline
\end{tabular}

Tabel 1 menunjukkan bahwa tingkat pendidikan responden di ruang rawat inap RSUD Tamiyang Layang sebagian besar adalah D3 Keperawatan yaitu sebanyak 30 orang $(69,8 \%)$, sebagian besar memiliki masa kerja lama (>3 tahun yaitu sebanyak 37 orang $(86 \%)$.

\section{b. Pelatihan responden}

Karakteristik

responden berdasarkan pelatihan yang diikuti dapat dilihat pada tabel 2 .

Tabel 2 Pelatihan Responden di Ruang Rawat Inap RSUD Tamiyang Layang

\begin{tabular}{cccc}
\hline No. & Pelatihan & \multicolumn{2}{c}{ Jumlah } \\
\cline { 3 - 4 } & $\begin{array}{c}\text { Frekuensi } \\
\text { (orang) }\end{array}$ & $\%$ \\
\hline 1 & Ada & 0 & 0 \\
\hline 2 & Tidak ada & 43 & 100 \\
\hline & Jumlah & 43 & 100 \\
\hline
\end{tabular}

Tabel 2 menunjukkan bahwa responden di ruang rawat inap RSUD Tamiyang Layang sebagian besar tidak ada mengikuti pelatihan apapun yaitu sebanyak 43 orang (100\%).

\section{Kepemimpinan kepala ruangan}

Kepemimpinan kepala ruangan di Ruang Rawat Inap RSUD Tamiyang Layang dapat dilihat pada tabel 3.

Tabel 3 Kepemimpinan Kepala Ruangan di Ruang Rawat Inap RSUD Tamiyang Layang.

\begin{tabular}{cccc}
\hline No. & $\begin{array}{c}\text { Kepemimpinan } \\
\text { Kepala } \\
\text { Ruangan }\end{array}$ & $\begin{array}{c}\text { Jrekuensi } \\
\text { (orang) }\end{array}$ & \% \\
\hline 1 & Baik & 30 & 69,8 \\
\hline 2 & Cukup & 13 & 30,2 \\
\hline 3 & Kurang & 0 & 0 \\
\hline & Jumlah & 43 & 100 \\
\hline
\end{tabular}

Tabel 3 menunjukkan bahwa kepemimpinan kepala ruangan di RSUD Tamiyang Layang sebagian besar sudah dengan kategori baik yaitu sebanyak 30 orang $(69,8 \%)$. Data tersebut menunjukkan 
bahwa kepala ruangan dalam menjalankan kepemimpinan saat pelaksanaan timbang terima sebagian besar sudah berusaha memberikan atau melakukan yang terbaik terhadap pelaksanaan timbang terima pasien.

\section{Pelaksanaan timbang terima}

Pelaksanan timbang terima di Ruang Rawat Inap RSUD Tamiyang Layang dapat dilihat pada tabel 4.

Tabel 4 Pelaksanaan Timbang Terima di Ruang Rawat Inap RSUD Tamiyang Layang

\begin{tabular}{|c|c|c|c|}
\hline \multirow[b]{2}{*}{ No. } & \multirow{2}{*}{$\begin{array}{c}\text { Pelaksanaan } \\
\text { Timbang } \\
\text { Terima }\end{array}$} & \multicolumn{2}{|c|}{ Jumlah } \\
\hline & & $\begin{array}{c}\text { Frekuensi } \\
\text { (orang) }\end{array}$ & $\%$ \\
\hline 1 & Baik & 32 & 74,4 \\
\hline 2 & Kurang baik & 11 & 25,6 \\
\hline & Jumlah & 43 & 100 \\
\hline
\end{tabular}

Tabel 4 menunjukkan bahwa pelaksanaan timbang terima di RSUD Tamiyang Layang sebagian besar dengan kategori baik yaitu sebanyak 32 orang $(74,4 \%)$. Data tersebut menunjukkan tindakan serah terima tanggung jawab pelayanan keperawatan pasien dari petugas jaga shift sebelumnya kepada petugas jaga shift selanjutnya sebagian besar sudah terlaksana sesuai dengan standar operasional yang telah ditetapkan rumah sakit.

\section{Hubungan kepemimpinan kepala ruangan dengan pelaksanaan timbang terima}

Hasil analisis hubungan kepemimpinan kepala ruangan dengan pelaksanaan timbang terima di RSUD Tamiyang Layang dapat dilihat pada tabel 5 .

Tabel 5. Hubungan Kepemimpinan Kepala Ruangan dengan Pelaksanaan Timbang Terima di Ruang Rawat Inap RSUD Tamiyang Layang

\begin{tabular}{cccccccc}
\hline \multirow{2}{*}{ No } & \multirow{2}{*}{$\begin{array}{c}\text { Kepemimpinan } \\
\text { Kepala Ruangan }\end{array}$} & \multicolumn{3}{c}{ Pelaksanaan Timbang Terima } & \multicolumn{2}{c}{ Jumlah } \\
\cline { 2 - 8 } & Baik & $\mathbf{f}$ & $\mathbf{\%}$ & $\mathbf{f}$ & $\mathbf{\%}$ & f & \% \\
\hline 1 & Baik & 30 & 100 & 0 & 0 & 30 & 100 \\
\hline 2 & Cukup & 2 & 15,4 & 11 & 84,6 & 13 & 100 \\
\hline & Jumlah & 32 & 74,4 & 11 & 25,6 & 43 & 100 \\
\hline
\end{tabular}

Tabel 5 menunjukkan bahwa dari kepemimpinan kepala ruangan yang baik seluruh perawat telah melaksanakan timbang terima yang baik yaitu sebanyak 30 orang (100\%) sedangkan dari kepemimpinan kepala ruang yang cukup sebagian besar timbang terima dilaksanakan dengan kategori kurang baik yaitu sebanyak 11 orang $(84,6 \%)$.
Hasil analisis dengan menggunakan uji statistik Spearman Rank didapatkan nilai $\mathrm{p}$ sebesar 0,000. Nilai tersebut secara statistik lebih kecil dari nilai $\alpha(0,05)$. Hal ini menunjukkan bahwa ada hubungan antara kepemimpinan kepala ruangan dengan pelaksaaan timbang terima di RSUD Tamiyang Layang pada Tahun 2019. Nilai korelasi Spearman Rank sebesar 0,891 menunjukkan bahwa kekuatan korelasi yang 
sangat kuat, dapat diartikan bahwa baik kepemipinan kepala ruangan maka akan semakin membaiknya pelaksanaan timbang terima yang dilakukan oleh perawat.

\section{PEMBAHASAN}

Kepala ruang perawatan merupakan nama jabatan yang diberikan kepada seorang tenaga keperawatan yang mempunyai tanggungjawab dan wewenang dalam mengatur dan mengendalikan kegiatan pelayanan keperawatan di ruang perawatan dengan latar belakang pendidikan minimal ahli madya keperawatan/kebidanan dan sudah pernah mengikuti kursus atau pelatihan manajemen pelayanan keperawatan ruang/bangsal, mempunyai pengalaman kerja perawat pelaksana 3-5 tahun dan kondisi fisik, sehat jasmani dan rohani (Tribowo, 2013).

Hasil penelitian ini sama dengan hasil penelitian Muhammad (2013) yang mendapatkan bahwa kepemimpinan kepala ruangan menurut persepsi perawat di Ruang Instalasi Rawat Inap F BLU RSUP Prof. Dr. R.D Kondou Manado seluruhnya dengan kategori baik yaitu sebanyak 12 orang (100\%). Hasil penelitian Pratiwi (2015) menunjukkan bahwa mutu kepemimpinan kepala ruangan di Rumah Sakit Siti Khadijah Sepanjang sebagian besar dalam kategori baik yaitu sebanyak 4 orang $(80 \%)$.

Pengetahuan kepala ruangan yang baik tentunya membuat kepala ruangan untuk mampu mengarahkan perawat dalam melaksanakan timbang terima. Pengarahan yang diberikan oleh kepala ruangan merupakan pedoman perawat dalam bekerja sehingga perawat lebih terarah dalam pelaksanaan serah terima pasien. Pada saat perawat mengalami kesulitan, kepala ruangan memberikan arahan dan tetap melibatkan perawat dalam menangani permasalahan yang dihadapi sehingga serah terima dapat terlaksana dengan baik.

Pelaksanaan prosedur timbang terima agar dapat terlaksana dengan baik dibutuhkan peran kepala ruangan sebagai manajer ruangan dimana salah satunya fungsinya adalah pengarahan. Bentuk fungsi pengarahan kepala ruangan antara lain adalah operan atau timbang terima. Fungsi pengarahan ini dilakukan oleh kepala ruangan dalam bentuk komunikasi yang efektif. Seorang pemimpin khususnya kepala ruangan atau ketua tim harus dapat mengarahkan stafnya karena implikasi fungsi pengarahan dapat meningkatkan kemampuan dan pemahaman perawat pelaksana tentang asuhan keperawatan, khususnya pelaksanaan timbang terima. Sebagai seorang pemimpin, kepala ruangan harus mengetahui bagaimana mengatur bawahannya dan mampu mempertahankan kualitas kerja. Pengarahan bisa mencakup penugasan, perintah atau instruksi yang mudah dimengerti dan diikuti oleh bawahannya agar tujuan organisasi khususnya asuhan keperawatan dapat tercapai dengan baik. Khusus pada pelaksanaan timbang terima, dengan adanya pengarahan yang baik diharapkan dapat meningkatkan kemampuan perawat dalam menjalin komunikasi antar perawat dan pemahaman tentang pentingnya timbang terima akan semakin baik (Alim, 2015).

Hasil penelitian ini sama dengan hasil penelitian Istiningtyas (2018) yang menunjukkan ada hubungan antara kepemimpinan kepala ruang saat handover dengan pelaksanaan handover di ruang rawat inap $(\mathrm{p}=0,0014)$.

\section{KESIMPULAN}

Kepemimpinan kepala ruangan di RSUD Tamiyang Layang sebagian besar sudah dengan kategori baik yaitu sebanyak 30 orang $(69,8 \%)$. Pelaksanaan timbang terima di RSUD Tamiyang Layang sebagian besar dengan kategori baik yaitu sebanyak 32 orang $(74,4 \%)$. Ada hubungan antara kepemimpinan kepala ruangan dengan pelaksaaan timbang terima di RSUD Tamiyang Layang Tahun 2019 dengan nilai p sebesar 0,000 dan koefisien korelasi sebesar 0,891 .

Sehingga, dapat disarankan perlunya pihak rumah sakit untuk lebih tegas dalam menindak keterlambatan perawat setiap pergantian shift, selain itu pihak rumah sakit hendaknya menghimbau kepala ruangan agar dapat lebih aktif mengikuti pelaksanaan timbang terima pasien sehingga kepala ruangan dapat lebih memiliki pengetahuan dalam pelaksanaan asuhan keperawatan khususnya pada proses perencanaan. Kepala ruangan hendaknya meningkatkan hubungan interpersonal dengan perawat pelaksana, selain itu hendaknya dapat 
meningkatkan kemampuan dalam manajemen konflik antar perawat pelaksana.

Perawat perlu mempertahankan dan meningkatkan kemampuan kerja khususnya kemampuan dalam pelaksanaan serah terima pasien melalui proses belajar, pendidikan dan pelatihan-pelatihan atau dengan cara mengikuti seminar-seminar keperawatan khususnya dalam pelaksanaan serah terima. Selanjutnya, perlunya penelitian lebih lanjut pelaksanaan serah terima pasien dengan meneliti variabel lainnya seperti faktor-faktor (usia, jenis kelamin, status perkawinan, tingkat pendidikan, lama kerja dan lingkungan kerja) yang berhubungan dengan timbang terima perawat.

\section{ACKNOWLEDGMENT}

Ucapan terimakasih kepada sahabat yaitu Septi Machelia C.N, dan rekan Maria Frani serta mahasiswa terkasih Ferra atas bantuan dalam penyelesaian penelitian ini.

\section{DAFTAR PUSTAKA}

Agustine, U. (2016). Hubungan Motivasi dan Karakteristik Demografi dengan Kinerja Perawat Puskesmas Sumba Timur. Jurnal Kesehatan Primer, 1(1), 28-37.

Alim, Y. (2015). Hubungan Pengarahan Kepala Ruangan dengan Pelaksanaan Timbang Terima Perawat di Ruang Rawat Inap RSUD Toto Kabila Kab. Bone Bolango. Diakses tanggal 19 Maret 2019, dari http://eprints.ung.ac.id/12419/

Apriani, F. (2019). Efek Psikososial pada Perawat Perempuan yang Menjalani Peran Ganda. Jurnal Kesehatan Saelmakers Perdana, 2 (1), 14-23.

Budiman., \& Riyanto. (2013). Kapita Selekta Kuesioner Pengetahuan dan Sikap dalam Penelitian Kesehatan. Jakarta: Salemba Medika.

Hasibuan, M. S.P. (2016). Manajemen Sumber Daya Manusia. Jakarta: PT Bumi Aksara

Istiningtyas, A. (2018). Hubungan Kepemimpinan Kepala Ruang saat Handover dengan Pelaksanaan Handover di Ruang Rawat Inap
RSUD Sukoharjo. Jurnal Kesehatan Kusuma Husada, 7 (2), 72-77.

Muhammad, H. Y. (2013). Hubungan Kepemimpinan Kepala Ruangan Menurut Persepsi Perawat terhadap Motivasi Kerja Perawat Pelaksana di Ruang Instalasi Rawat Inap F BLU RSUP Prof. Dr. R.D Kondou Manado. Ejournal Keperawatan, 1 (1) 1-9.

Pobas, S. (2018). Evaluasi Timbang Terima Pasien oleh Perawat di Ruang Rawat Inap Rumah Sakit Suaka Insan Banjarmasin. Jurnal Keperawatan Suaka Insan, 3 (2) 1-9.

Raodhah, S. (2017). Hubungan Peran Kepala Ruangan dengan Kinerja Perawat di Ruang Rawat Inap RSUD Syekh Yusuf Kabupaten Gowa. Al-Shihah Publich Health Science Journal, 9 (1), 94-102.

Sari, N. L. (2015). Hubungan Beban Kerja, Faktor Demografi, Locus of Control dan Harga Diri terhadap Burnout Syndrome pada Perawat Pelaksana IRD RSUP Sanglah. Community of Publishing in Nursing Journal, 3(1), 5160.

Suni, A. (2018). Kepemimpinan dan Manajemen Keperawatan. Jakarta: Bumi Medika.

Tribowo, C. (2013). Manajemen Pelayanan Keperawatan di Rumah Sakit. Jakarta: Trans Info Media. 